\title{
PSYCHOLOGY
}

\section{СЕМАНТИКО-СМЫСЛОВОЙ ПОДХОД К ЛИТЕРАТУРНОМУ ТВОРЧЕСТВУ И ЗНАЧИМЫЕ ДРУГИЕ КАК ПРОТОТИПЫ ЛИТЕРАТУРНЫХ ГЕРОЕВ}

\author{
Сапрыгина Н. В.,
}

Одесский национальный университет имени И. И. Мечникова, доцент кафедры социальной и прикладной психологии, кандидат филологических наук, Украина, г. Одесса

DOI: https://doi.org/10.31435/rsglobal_sr/28022019/6367

\section{ARTICLE INFO}

Received 14 December 2018 Accepted 22 February 2019

Published 28 February 2019

\section{KEYWORDS}

literary work, semantic-andsense approach, virtual communication, real communication, art communication, dialogue, significant other, character, prototype, creative idea. \begin{abstract}
We have proposed a new complex semantic-and-sense approach to the study of literary creativity and cultural phenomena. It is based on psychological ideas about real and virtual communication processes, about the cognitive component of a literary work based on the author's personal sense.

Creating of a literary work is not only processing the products of imagination, but also responding to the real author's communicants. We have shown that among the prototypes of famous literary characters an important part is represented by the author's significant others. Transforming the image of a significant other into a prototype and into a literary character can be considered an effect, showing how real communication becomes the part of writer's creative process.
\end{abstract}

Citation: Сапрыгина Н. B. (2019) Semantic-and-Sense Approach to Literary Creativity and Significant Others as Prototypes of Literary Characters. Science Review. 2(19). doi: 10.31435/rsglobal_sr/28022019/6367

Copyright: (c) 2019 Сапрыгина Н. В. This is an open-access article distributed under the terms of the Creative Commons Attribution License (CC BY). The use, distribution or reproduction in other forums is permitted, provided the original author(s) or licensor are credited and that the original publication in this journal is cited, in accordance with accepted academic practice. No use, distribution or reproduction is permitted which does not comply with these terms.

Цель: обосновать принципы нового комплексного семантико-смыслового подхода к продуктам литературного творчества как явлениям культуры и показать примеры его применения.

Объект: система «автор - текст - читатель».

Предмет: новый комплексный семантико-смысловой подход к системе «автор - текст читатель»; коммуникативная составляющая творческого замысла.

Изучая систему «автор - текст - читатель», мы видим в ней двух субъектов и один объект (информационный). Этот объект нематериален - передаёт идеи. Идеи попадают в психику читателя, который их сохраняет и преобразует. В этой системе видим взаимодействие текстов (информации), индивидов и влияющей на них внетекстовой и внепсихической реальности. Сложность и разноплановость этих объектов обусловливает их исследования в руслах разных дисциплин. Следовательно, для понимания взаимодействия в системе АТЧ необходима междисциплинарность и, помимо обнаружения нового, актуально необходима интеграция уже изученных закономерностей.

Соединение знаний из области разных, но близких дисциплин уже происходит границы наук меняются. Однако, не механическое и не смешивающее всё похожее. Соединение тех фактов и закономерностей, которые соответствуют определённой цели, а именно - 
раскрыть особенности художественного творчества и взглядов автора, их понимание читателем.

Междисциплинарность выражается в интегративном подходе. Это первый из использованных нами подходов.

Второй подход - коммуникативный. Его иногда называют диалогическим.

Текст создаётся автором не для себя или не только для себя. Писателю нужен отклик, нужен понимающий читатель. Автор общается не только с воображаемыми читателями, но и с реальными людьми, которые становятся его собеседниками. Исходя из этого, нужно изучать текст во взаимосвязи с культурным пространством и реальным окружением писателя.

Третье. Интеграция психологических знаний. Автор и читатель - личности. В их взаимодействии, создании и воздействии текста, в понимании, эмоциональном реагировании проявляются психологические закономерности, в частности, социально-психологические закономерности общения, общепсихологические закономерности понимания, психологические закономерности художественного творчества. Эту интеграцию психологических знаний осуществляла психолингвистика. Но если рассматривается художественная литература, то эти закономерности шире тех, что изучает психолингвистика.

Четвёртый подход, или, скорее, принцип - иерархический. Обратиться к устройству текста. Подниматься от закономерностей языка и лексической семантики до семантики различных структур текста и семантики коммуникации. При необходимости спускаться по иерархической лестнице до анализа семантики отдельных слов.

Пятый подход предполагает обращение к истории. Это культурно-исторический подход. Произведение рождено в некоем историческом пространстве - ему предшествовали события, известные автору и переживаемые им. Читателям другого времени они могут быть неизвестны, смутно вспоминаемы и непонятны. Постараться восстановить историческую канву для данного произведения - синхронную или более давнюю, если о ней упоминает автор.

К нему примыкает шестой подход - биографический, в русле которого предполагается связь произведения и биографии его автора.

Для обоснования новых данных об этой взаимосвязи используется разработанный в советской психологии принцип единства личности, сознания и деятельности С.Л. Рубинштейн [12], Б.Г. Ананьев [2], А.Н. Леонтьев [9] и др.) Поэтому закономерен седьмой подход личностный. Как уже сказано, автор и читатель - личности. У автора есть свои психологические особенности и свои ценности. Отсюда своеобразие эмоций. Разные писатели любят и ненавидят не одно и то же.

Всё вместе взятое указывает на важность категории «знание» для понимания художественного текста читателями - от самого наивного читателя до учёного-специалиста. Разумеется, знания у автора и читателей разных уровней различны. Для специалиста важно стремление реконструировать знания автора. Отсюда восьмой подход - когнитивный.

Последний подход, девятый, исходит из принципа уникальности текста и порождающей его личности, и называется идиографическим (в переводе книги Г. Олпорта «Становление человека» [11] он назван идеографическим). Уникальной является и биография автора, и ситуация, вызвавшая переживания, аккумулирующиеся в виде творческого замысла.

Наш собственный подход, в той или иной мере опирающийся на все вышеназванные подходы, мы назвали семантико-смысловым.

Исходя из понимания смыслов психологом Д. А. Леонтьевым, «смысл объектов и явлений действительности является, по сути, системным качеством, которое они приобретают в контексте жизненного мира субъекта» [10, с.390] Д. А. Леонтьев ставит вопрос: «Что дают личности смыслы, содержащиеся в произведениях искусства»? [10, с.386].

Исходя из современных психологических исследований категории «смысл» $[4 ; 7 ; 8 ; 15$; 16], можно дать ей такое определение. Смысл - метакогнитивное интегральное образование психики, продукт субъективного кодирования представлений о мотивах, целях, выборе, ценностях, результатах активности или деятельности. С нашей точки зрения, смыслы коммуникации - те же психологические феномены, что и смыслы деятельности вне общения, призванные упорядочивать активность индивида, делая её понятной и целесообразной (ответ на вопрос «зачем?»), только имеющие более узкую область приложения. Семантико-смысловой подход даёт возможность выявлять неочевидные, но влияющие смыслы в коммуникации; а в 
литературном произведении - те смыслы, что не попали в поле зрения литературоведов и читателей ранее, выявлять подтексты, связи с биографией автора. Смыслы являются психическими знаковыми образованиями, обладающими семантической (информационной) природой. Они отображают конфликт, каким его видит автор, переживания и поиски решения конфликта. В отличие от компонентов содержания, которые отвечают на вопросы «кто, что и как», смыслы отвечают на вопрос «зачем» и выражают представление о мотивах и целях конфликта и путях его разрешения.

Представим примеры использования семантико-смыслового подхода. При помощи этого подхода можно получить данные, относящиеся к психологии творчества, и прежде всего к таким феноменам, как художественный замысел и художественный образ персонажа (героя).

Благодаря использованию выдвигаемого подхода нами обнаружен феномен выбора прототипа героя художественного произведения из круга общения автора, а именно, из числа близких и знакомых автору людей.

Известно, что в процессе общения каждый коммуникант создаёт в своём представлении образ другого коммуниканта и адресует свои трансакции этому образу. В художественной коммуникации, по нашим данным, образ авторского значимого другого превращается в образ героя. Исходя из законов художественного творчества, образ персонажа становится несколько иным, чем представление о реальном человеке.

Изображённый таким способом человек может ответить аналогичным образом, то есть изобразить художественными средствами автора, создавшего его образ. Пример мы находим в художественном диалоге Тургенева и Достоевского.

Помимо круга близких и знакомых, существуют и другие источники возникновения образов литературных героев. Это герои других произведений, а также исторические личности. В случае создания образа героя с опорой на образ уже известного персонажа можно говорить о литературном влиянии другого произведения.

О прототипах литературных произведений написано много литературоведческих работ. Отмечаем разногласия в точках зрения о том, кто именно является прототипом конкретного героя. Знания о прототипах добавляются в копилку историко-культурных фактов. Нас интересует психологическая природа явления трансформации прототипа в образ героя.

В литературоведческом термине «прототип» под прототипом понимают индивида, конкретное лицо, чей образ послужил основой для создания художественного образа писателем. То есть прототип - это человек, который находится в реальности. С точки зрения семантики этот термин неверен, так как слово «прототип» означает первообраз. Человек не является образом; его образ находится либо в психике других в виртуальном пространстве сознания, либо в передаваемой информации о человеке. И то и другое - вне объективной реальности. Значит, в термине «литературный прототип» смешивается реальность и знание о ней. Для психолога это может быть серьёзным затруднением, поэтому требуется уточнение терминов. «Прототип» как термин когнитивной психологии - обобщённое понятие о сходных предметах, которое возникло в психике на основе познания этих предметов в реальности [14, c. 135-161]. В когнитивной психологии теория прототипов показывает, как происходит процесс узнавания предметов реальности. Это сравнение их с уже известными образами - прототипами. Здесь прототип находится в психике воспринимающего. В значении близком к понятию литературного прототипа, в когнитивной психологии употребляется термин «эталон» уникальный объект, находящийся в реальности, знание о котором необходимо для опознания. Знание о человеке, послужившем первообразом, отчасти отражается (в формах, подобных впечатлению), отчасти конструируется автором. Создаётся образ виртуального субъекта, который называется герой, или персонаж (англ. character). Итак, следует уточнить: «прототип это человек, воспринимаемый образ которого был для автора эталоном при создании образа героя (персонажа) художественного произведения».

В свете предлагаемого подхода нами были изучены данные о прототипах героев известных литературных произведений. Всего рассмотрено 40 прототипов. Не обсуждаем, достаточно ли было оснований у литературоведов называть именно этих людей прототипами известных персонажей. Основания эти заключены в семантических характеристиках персонажей - словах, описывающих их внешность, черты характера и поступки. Условно 
принимаем положение, что прототипы литературоведами распознаны верно. Предполагаем, что у каждого героя был только один прототип (хотя возможны и несколько).

Данные об известных прототипах сведены в таблицу.

Таблица 1. Герои литературных произведений и их прототипы

\begin{tabular}{|c|c|c|c|c|c|c|c|}
\hline № & 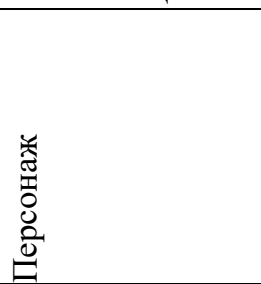 & 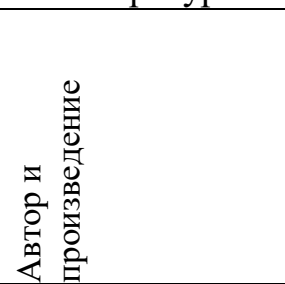 & 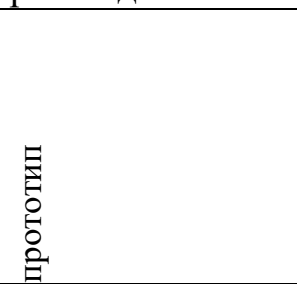 & 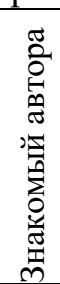 & 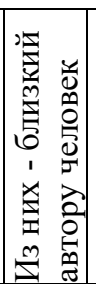 & 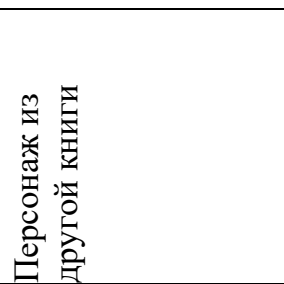 & 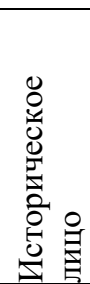 \\
\hline 1 & 2 & 3 & 4 & 5 & 6 & 7 & 8 \\
\hline 1 & Айболит & $\begin{array}{l}\text { Корней } \\
\text { Чуковский } \\
\text { «Доктор } \\
\text { Айболит» }\end{array}$ & П.В.Изергин, врач & + & & $\begin{array}{l}\text { Д-р Дулитл } \\
\text { (Х.Лофтинг } \\
\text { «Истории доктора } \\
\text { Дулитла») }\end{array}$ & \\
\hline 2 & Алиса & $\begin{array}{l}\text { Льюис Кэролл } \\
\text { «Алиса в стране } \\
\text { чудес», «Алиса в } \\
\text { Зазеркалье» }\end{array}$ & Алиса Лиддел & + & + & & \\
\hline 3 & Д’Артаньян & $\begin{array}{l}\text { Александр Дюма } \\
\text { «Три мушкетера» }\end{array}$ & $\begin{array}{l}\text { Шарль Ожье де } \\
\text { Батц де } \\
\text { Кастельмор, граф } \\
\text { д’Артаньян }\end{array}$ & & & $\begin{array}{l}\text { «Мемуары } \\
\text { господина } \\
\text { д’Артаньяна» }\end{array}$ & + \\
\hline 4 & Беатриче & $\begin{array}{l}\text { Данте } \\
\text { «Божественная } \\
\text { комедия» }\end{array}$ & Беатриче & + & + & & \\
\hline 5 & $\begin{array}{l}\text { Бриан де } \\
\text { Буагильбер }\end{array}$ & $\begin{array}{l}\text { Вальтер Скотт } \\
\text { «Айвенго» }\end{array}$ & Брайан де Джей & & & & + \\
\hline 6 & Остап Бендер & $\begin{array}{l}\text { И.Ильф, Е.Петров } \\
\text { «Двенадцать } \\
\text { стульев», «Золотой } \\
\text { телёнок» }\end{array}$ & Осип Шор & + & & & \\
\hline 7 & Остап Бульба & $\begin{array}{l}\text { Н.В.Гоголь } \\
\text { «Тарас Бульба» }\end{array}$ & Остап Гоголь & & & & + \\
\hline 8 & Майор Вихрь & $\begin{array}{l}\text { Юлиан Семёнов } \\
\text { Майор Вихрь» }\end{array}$ & Овидий Горчаков & + & & & \\
\hline 9 & $\begin{array}{l}\text { Татьяна } \\
\text { Власенкова }\end{array}$ & $\begin{array}{l}\text { В.Каверин } \\
\text { «Открытая книга» }\end{array}$ & $\begin{array}{l}\text { 3.В.Ермольева, } \\
\text { микробиолог }\end{array}$ & + & & & \\
\hline 10 & $\begin{array}{l}\text { Маргарита } \\
\text { Готье }\end{array}$ & $\begin{array}{l}\text { А.Дюма-сын } \\
\text { «Дама с } \\
\text { камелиями» }\end{array}$ & Мари Дюплесси & + & + & & \\
\hline 11 & Дориан Грэй & $\begin{array}{l}\text { Оскар Уайльд } \\
\text { «Портрет } \\
\text { Дориана Грэя» }\end{array}$ & Джон Грэй & + & + & & \\
\hline 12 & Бессонов & $\begin{array}{l}\text { А.Н.Толстой } \\
\text { «Хождение по } \\
\text { мукам» }\end{array}$ & Александр Блок & + & & & \\
\hline 13 & Анна Каренина & $\begin{array}{l}\text { Лев Толстой } \\
\text { «Анна Каренина» }\end{array}$ & $\begin{array}{l}\text { Мария Гартунг, } \\
\text { дочь А.С.Пушкина }\end{array}$ & + & & & \\
\hline 14 & $\begin{array}{l}\text { Кристофер } \\
\text { Робин }\end{array}$ & $\begin{array}{l}\text { А.А. Милн } \\
\text { «Винни-Пух и } \\
\text { все-все-все» }\end{array}$ & Сын писателя & + & + & & \\
\hline 15 & Робинзон Крузо & $\begin{array}{l}\text { Д. Дефо. } \\
\text { Приключения } \\
\text { Робинзона Крузо» }\end{array}$ & $\begin{array}{l}\text { Александр } \\
\text { Селькирк }\end{array}$ & & & & + \\
\hline 16 & Джордж & $\begin{array}{l}\text { Дж.К.Джером } \\
\text { «Трое в одной } \\
\text { лодке» }\end{array}$ & Джордж Уингрейв & + & + & & \\
\hline 17 & Харрис & $\begin{array}{l}\text { Дж.К.Джером } \\
\text { «Трое в одной } \\
\text { лодке» }\end{array}$ & Карл Хенчель & + & + & & \\
\hline
\end{tabular}


Продолжение таблицы 1.

\begin{tabular}{|c|c|c|c|c|c|c|c|}
\hline 1 & 2 & 3 & 4 & 5 & 6 & 7 & 8 \\
\hline 18 & $\begin{array}{l}\text { Лучиэнь } \\
\text { Тинувиэль }\end{array}$ & $\begin{array}{l}\text { Д.Р.Толкиен } \\
\text { «Сильмариллион }\end{array}$ & $\begin{array}{l}\text { Эдит Толкиен, } \\
\text { жена писателя }\end{array}$ & + & + & & \\
\hline 19 & Маргарита & $\begin{array}{l}\text { М.Булгаков } \\
\text { «Мастер и } \\
\text { Маргарита» }\end{array}$ & $\begin{array}{l}\text { Елена Булгакова, } \\
\text { жена писателя }\end{array}$ & + & + & & \\
\hline 20 & $\begin{array}{l}\text { Григорий } \\
\text { Мелехов }\end{array}$ & $\begin{array}{l}\text { М. Шолохов } \\
\text { «Тихий Дон» }\end{array}$ & $\begin{array}{l}\text { Харлампий } \\
\text { Ермаков }\end{array}$ & + & & & \\
\hline 21 & $\begin{array}{l}\text { Граф Монте- } \\
\text { Кристо }\end{array}$ & $\begin{array}{c}\text { Александр Дюма } \\
\text { кГраф Монте-Кристо» }\end{array}$ & Франсуа Пико & & & & + \\
\hline 22 & Негурова & $\begin{array}{l}\text { М.Ю. Лермонтов } \\
\text { «Княгиня Лиговская» }\end{array}$ & $\begin{array}{l}\text { Екатерина } \\
\text { Сушкова }\end{array}$ & + & + & & \\
\hline 23 & Евгений Онегин & $\begin{array}{l}\text { А. С.Пушкин } \\
\text { «Евгений Онегин» }\end{array}$ & $\begin{array}{l}\text { П.А. Катенин, } \\
\text { поэт }\end{array}$ & + & & & \\
\hline 24 & Пат & $\begin{array}{l}\text { Э.М. Ремарк } \\
\text { «Три товарища» }\end{array}$ & $\begin{array}{l}\text { Ильзе Ютте } \\
\text { Замбоне, жена } \\
\text { писателя }\end{array}$ & + & + & & \\
\hline 25 & $\begin{array}{l}\text { Володя } \\
\text { Патрикеев }\end{array}$ & $\begin{array}{l}\text { А.Козачинский } \\
\text { «Зелёный фургон» }\end{array}$ & Евгений Петров & + & & & \\
\hline 26 & Пиковая дама & $\begin{array}{l}\text { А.С. Пушкин. } \\
\text { «Пиковая дама» }\end{array}$ & $\begin{array}{l}\text { Княгиня } \\
\text { Н.П.Голицына }\end{array}$ & + & & & \\
\hline 27 & Пиноккио & $\begin{array}{l}\text { Карло Коллоди } \\
\text { «Приключения } \\
\text { Пиноккио» }\end{array}$ & Пиноккио Санчес & & & & + \\
\hline 28 & Гарри Поттер & $\begin{array}{l}\text { Дж. Роулинг } \\
\text { «Гарри Поттер» }\end{array}$ & Иэн Поттер & + & + & & \\
\hline 29 & $\begin{array}{l}\text { Профессор } \\
\text { Преображенский }\end{array}$ & $\begin{array}{l}\text { М.Булгаков } \\
\text { «Собачье сердце» }\end{array}$ & $\begin{array}{l}\text { Проф. } \\
\text { Покровский, дядя } \\
\text { писателя }\end{array}$ & + & + & & \\
\hline 30 & Пьеро & $\begin{array}{l}\text { А.Толстой } \\
\text { «Золотой ключик, } \\
\text { или Приключения } \\
\text { Буратино» }\end{array}$ & Александр Блок & + & & $\begin{array}{l}\text { Персонаж комедии } \\
\text { дель арте;/ персонаж } \\
\text { пьесы А.Блока } \\
\text { «Балаганчик» }\end{array}$ & \\
\hline 31 & Питер Пэн & $\begin{array}{l}\text { Джеймс Барри } \\
\text { «Питер Пэн», «Питер } \\
\text { Пэн и Венди» }\end{array}$ & $\begin{array}{l}\text { Майк Ллевелин } \\
\text { Дэвис }\end{array}$ & + & & & \\
\hline 32 & $\begin{array}{l}\text { Академик } \\
\text { Рядно }\end{array}$ & $\begin{array}{l}\text { В. Дудинцев } \\
\text { «Белые одежды» }\end{array}$ & $\begin{array}{l}\text { академик } \\
\text { Т.Д.Лысенко }\end{array}$ & & & & + \\
\hline 33 & Наташа Ростова & $\begin{array}{l}\text { Л.Толстой } \\
\text { «Война и мир» }\end{array}$ & $\begin{array}{l}\text { Татьяна Берс, сестр } \\
\text { жены писателя }\end{array}$ & + & + & & \\
\hline 34 & Том Сойер & $\begin{array}{l}\text { Марк Твен } \\
\text { «Приключения } \\
\text { Тома Сойера» }\end{array}$ & Томас Сойер & + & & & \\
\hline 35 & Саня Григорьев & $\begin{array}{l}\text { В.Каверин «Два } \\
\text { капитана» }\end{array}$ & $\begin{array}{l}\text { Полярный лётчик } \\
\text { С.Леваневский }\end{array}$ & + & & & \\
\hline 36 & Суок & $\begin{array}{l}\text { Ю. Олеша «Три } \\
\text { толстяка» }\end{array}$ & $\begin{array}{l}\text { Серафима Суок, } \\
\text { сестра жены } \\
\text { писателя }\end{array}$ & + & + & & \\
\hline 37 & Бекки Тэтчер & $\begin{array}{l}\text { Марк Твен } \\
\text { «Приключения } \\
\text { Тома Сойера» }\end{array}$ & Лора Хокинс & + & & & \\
\hline 38 & Шерлок Холмс & $\begin{array}{l}\text { А. Конан Дойль. } \\
\text { «Приключения } \\
\text { Шерлока Холмса» }\end{array}$ & $\begin{array}{l}\text { Джозеф Белл, } \\
\text { врач }\end{array}$ & + & & & \\
\hline 39 & Чацкий & $\begin{array}{l}\text { А.С.Грибоедов } \\
\text { «Горе от ума» }\end{array}$ & П.Я.Чаадаев & + & & & \\
\hline 40 & Штирлиц & $\begin{array}{l}\text { Юлиан Семёнов } \\
\text { «Семнадцать } \\
\text { мгновений весны» }\end{array}$ & $\begin{array}{l}\text { Гауптштурмфюрер } \\
\text { СС Вилли Леман }\end{array}$ & & & & + \\
\hline \multirow{2}{*}{\multicolumn{2}{|c|}{ Всего }} & \multirow[t]{2}{*}{38} & \multirow[t]{2}{*}{40} & \multirow[t]{2}{*}{32} & \multirow[t]{2}{*}{15} & 3 & 8 \\
\hline & & & & & & \multicolumn{2}{|l|}{$\begin{array}{l}\text { отмечены дважды - } 3 \\
\text { персонажа }\end{array}$} \\
\hline
\end{tabular}


Несмотря на то, что данные нуждаются в обогащении и уточнении, можно сделать вывод, что подавляющее большинство прототипов (32 из 40) взято из круга знакомых автора. Из них почти половина - близкие автору люди.

Значит, преобразование прототипа в героя - не просто использование наблюдений автора, а обращение к значимому другому.

Значимый другой - «личность, образ которой, отраженный в психике других людей, оказывает на них влияние. Оно выражается в изменении их мотивационно-смысловой и эмоциональной сфер» [3]. «Личность, оказывающая влияние на других людей, что выражается в качественном изменении их смыслов» [6].

Это человек, чей образ составляет часть нашего «я». От этой личности и от нашего внутреннего образа этого другого зависят наши ценности, наши чувства и принимаемые решения.

Важно наличие взаимоотношений (диалога) со значимым другим или его образом, соответствующие ожидания (экспектации) [1].

Так, идеальное «я〉 подростка может быть скопировано с личности значимого другого, авторитетной в обществе. От этого образа зависит формирование идентичности будущего взрослого, в частности, выбор профессии.

Именно этим - способностью менять смыслы и влиять на чувства адресата интересуют писателя значимые другие, с которых он лепит образы своих героев. Образы героев, в свою очередь, также должны обладать способностью влияния.

А. В. Петровский [12] выделил 3 фактора влияния, наличествующие у значимого другого - авторитетность, власть и привлекательность. Эти характеристики другого в восприятии коммуниканта могут быть выражены в разной степени, даже со знаком минус. Возникают «межиндивидуальные связи, базирующиеся на чувствах «симпатии-антипатии» [5].

Логично продолжить: важным является такой момент, что другой не оставляет коммуниканта равнодушным. При отсутствии в общении эмоционального компонента реагирования на другого этот другой не является значимым.

Поэтому изображение прототипов в художественном произведении не просто срисовывание натурщиков, как полагали ранее. (Хотя компонент копирования реальности присутствует в любом творчестве.)

Разница не только в том, что в теории прототипов рассматривались неодушевлённые объекты, а в художественном творчестве возникают образы людей. Понятно, что к человеку отношение иное, чем к предмету. Суть в глубине познания этого другого - изображаемого субъекта. Значимые другие как прототипы глубоко интегрированы в психику писателя. Это личности, с которыми протекали сложные и продолжительные межличностные отношения, реальные диалоги и внутренние виртуальные. Значимые другие выступают носителями идей (взглядов, планов), не тождественных тем, которые есть у автора. При столкновении с ними автор испытывает внутренний конфликт: принять или не принять, рассматривает, взвешивает, смотрит, к чему приведёт идея, наконец, соглашается или отвергает.

Мы отмечаем, что среди прототипов оказываются писатели (Александр Блок, Овидий Горчаков). Они являются участниками диалога, репликами в котором служит произведение как своеобразный ответ - согласие (Семёнов - Горчаков) или возражение (А. Н. Толстой Александр Блок). Опираясь на опознание прототипов, можно выявить степень влияния одного автора на другого и шире - создателя одной информации на трансляторе другой. Если автор изобразил другого в качестве прототипа со знаком плюс (согласие, принятие), то это влияние значительно, и не только влияние текстов, но и личности.

Более примитивную аналогию прослеживаем в обыденном общении, когда нужно транслировать поучение адресату, не высказывая его прямо. Мать говорит дочке, которая хнычет и капризничает: «Это не Надя плачет, это Гадька плачет». Мать создаёт виртуальный образ третьего лица из черт собеседника-дочки. Девочка видит себя со стороны, узнаёт и стремится исправиться, но не обижается: ведь мама говорит не о ней. Разумеется, создание художественного образа персонажа не сводится к поучению. Персонаж становится транслятором или указателем ценностей.

Также видим создание образов исторических лиц и заимствование персонажей из других книг. Эти явления известны и для нас интереса не представляют. 
Главное наблюдаемое нами явление можно называть коммуникативной (диалогической) составляющей творческого замысла, а выявленную закономерность - эффектом превращения образа значимого коммуниканта в образ персонажа произведения. Это переход реальной коммуникации в виртуальную и формирование ядра замысла. Творческий процесс обладает диалогической природой.

Наблюдаемая закономерность может пригодиться для уточнения обстоятельств биографии писателей и для проблемы авторства. В выборе прототипов наблюдаем автобиографичность художественного творчества. Узнавание прототипов, если иметь в виду не поверхностное сходство, а сходство поведения и идей, на что можно опираться, даст новые знания о круге общения автора-коммуниканта, сфере влияющих на него лиц, фактах трансляции идей, обстоятельств жизни и духовной эволюции писателей.

Также данный эффект важен для выяснения закономерностей выявления истины/лжи/достоверности в сообщении, содержащем элементы вымысла. Углубляет наши знания о психологии и механизмах творческого процесса.

\section{REFERENCES}

1. Abulkhanova-Slavskaya K.A, Gordienko Ye. V. What does a person think about the significant other's attitude towards him // Psychological Journal. 2001. № 5. p. 38-47.

2. Ananyev B.G. Psychology and problems of human knowledge. Moscow, 1996.

3. Antsupov A.Ya., Shipilov A.I. Conflictologist dictionary. Moscow, 2006.

4. Dolzhenko V.Yu. Formation of the category of "meaning" as a problem of historical and psychological research. Thesis... cand. psychol. sciences. Barnaul, 2001. 153 p.

5. Kondratyev M. Yu., Il'in V. A. The Alphabet of Social Psychology and Practice. Moscow, 2007.

6. Kondratyev M.Yu. "Significant other": the components of interpersonal importance // Social Psychology and Society. 2011. № 2, p. 17-28.

7. Kravets A.C. Activity paradigm of meaning // Voronezh University Bulletin. Series "Humanities". 2003. №1, p.160-188.

8. Lavrinenko V.A. Psychological features of meaning sphere formation in teenagers // Psychology and personality. 2013. № 1 (3), p. 59-74.

9. Leontyev A.N. Activity. Consciousness. Personality. Moscow, 1975.

10. Leontyev D.A. Psychology of meaning: nature, structure and dynamics of meaning reality. Moscow, 2007.

11. Allport G.W.Г. Becoming: Basic Considerations for a Psychology of Personality. Moscow, 2002. [In Russian]

12. Petrovsky A.V. Three-factor model of a significant other // Issues of psychology. 1991. № 1, p. 7-18.

13. Rubinstein S.L. The problem of activity and consciousness in the system of Soviet psychology. Scholarly notes of Moscow State University. Issue 90. 1945.

14. Solso R. L. Cognitive psychology. Saint Petersburg, 2006. [In Russian].

15. Husid A.D. Features of decoding meanings in media by different social groups. Thesis... cand. psychol. sciences. - Moscow, 2011. $160 \mathrm{p}$.

16. Shevchenko N. The evolution of the category of "meaning" in the psychological activity theory // Psychology and society. 2012. № 1, p. 82-88. 